\title{
Residual Stress States After Piezo Peening Treatment at Cryogenic and Elevated Temperatures Predicted by FEM Using Suitable Material Models
}

\author{
Alexander Klumpp ${ }^{1, a^{*}}$, Mehmet Tamam ${ }^{1, b}$, Franziska Lienert ${ }^{1, \mathrm{c}}$, \\ Stefan Dietrich ${ }^{1, d}$, Jens Gibmeier ${ }^{1, e}$ and Volker Schulze ${ }^{1, f}$ \\ ${ }^{1}$ Karlsruhe Institute of Technology, Kaiserstraße 12, 76131 Karlsruhe, Germany

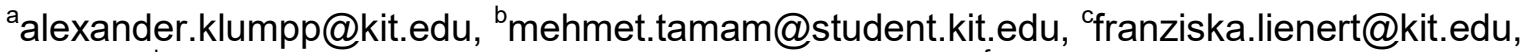 \\ d'stefan.dietrich@kit.edu, ${ }^{\mathrm{e}} \mathrm{jens.gibmeier@kit.edu,}{ }^{\mathrm{f}}$ volker.schulze@kit.edu
}

Keywords: Mechanical Surface Treatment, Machine Hammer Peening, Piezo Peening, Residual Stresses, Finite Element Simulation, Temperature Variation, Material Modeling

\begin{abstract}
Piezo peening is a recently developed mechanical surface treatment and belongs to machine hammer peening technologies. It has proven suitable to generate a wide range of compressive residual stress profiles and penetration depths depending on the parameters chosen for the process. By this means, greatly enhanced fatigue behavior could be achieved. In this study, the residual stress states after modified piezo peening treatments were determined experimentally and by 3D finite element (FE) simulation. Low alloy steel AISI 4140 was treated at ambient, cryogenic and elevated temperatures. Residual stresses were determined experimentally using the $\sin ^{2}(\psi)$ method combined with subsequent electrolytic surface layer removal. The FE simulation makes use of a material model, which is capable of describing strain-rate and temperature dependent material behavior as well as the Bauschinger effect and allows for the emulation of surface layer removal for proper residual stress determination. Thus, the applicability of appropriate material modeling to predict experimentally determined residual stress profiles could be demonstrated.
\end{abstract}

\section{Introduction}

Due to the generation of smooth surfaces together with compressive residual stresses and work hardening, machine hammer peening (MHP) has become a crucial process step, e.g. in the fabrication of molds and dies. Mostly utilizing electromagnetic, pneumatic and hydraulic transducers, today's MHP processes allow for the generation of specific surface characteristics [1].

A recently developed MHP technology utilizing a piezo-electric power transducer is piezo peening [2]. It has been applied to the quenched and tempered steel AISI4140, where the fatigue strength could be greatly improved. This was found to be mainly due to the introduction of nearsurface compressive residual stress fields. It was shown that residual stress profiles can widely be varied depending on the applied process parameters [2]. During the last decades, computational mechanics such as the finite element (FE) method has been applied extensively to understand process-property-relationships. Therefore an approach towards the FE simulation of piezo peening has been presented in a recent publication [3], showing good agreement between numerical and experimental results. Since strain-rate and temperature dependent material modeling has been applied in simulation, it is particularly interesting to investigate the influences of temperature variation upon flow stresses and residual stress profiles. On the one hand, potential influences of cryogenic and elevated temperatures on the residual stress profiles after piezo peening are explored experimentally, since the effect of temperature on residual stress generation has not yet been investigated for this process. Furthermore, tendencies regarding residual stress maxima and penetration depths in experiment and simulation are compared, such that the obtained results serve as validation for the applied material model. 


\section{Process Description and Experimental Setup}

A schematic drawing of the utilized piezo peening device [2] is shown in Fig. 1 (left). Specimens are mounted to a linear $x-y$-slide to be peened by the spherical hammer head. The latter is driven by the piezo actuator with a specific frequency (f), stepover distance (s) and stroke (h), generating "impulsive regular" [4] deformation of the specimen surface. By means of the x-y-slide, the work piece surface can be treated using different patterns, such as meanders. The soft bearing on top is used to control the contact properties. The hammer head is lifted off the specimen surface after each stroke. In Fig. 1 (right), the experimental setup for piezo peening at cryogenic temperatures is shown. Specimens were cooled down to $-180{ }^{\circ} \mathrm{C}$ using liquid $\mathrm{N}_{2}$ flowing through a brass block specimen holder. For piezo peening at elevated temperatures, the same block was heated by heating rods, thus achieving temperatures of $+200{ }^{\circ} \mathrm{C}$. In each case a two-point temperature controller was used.
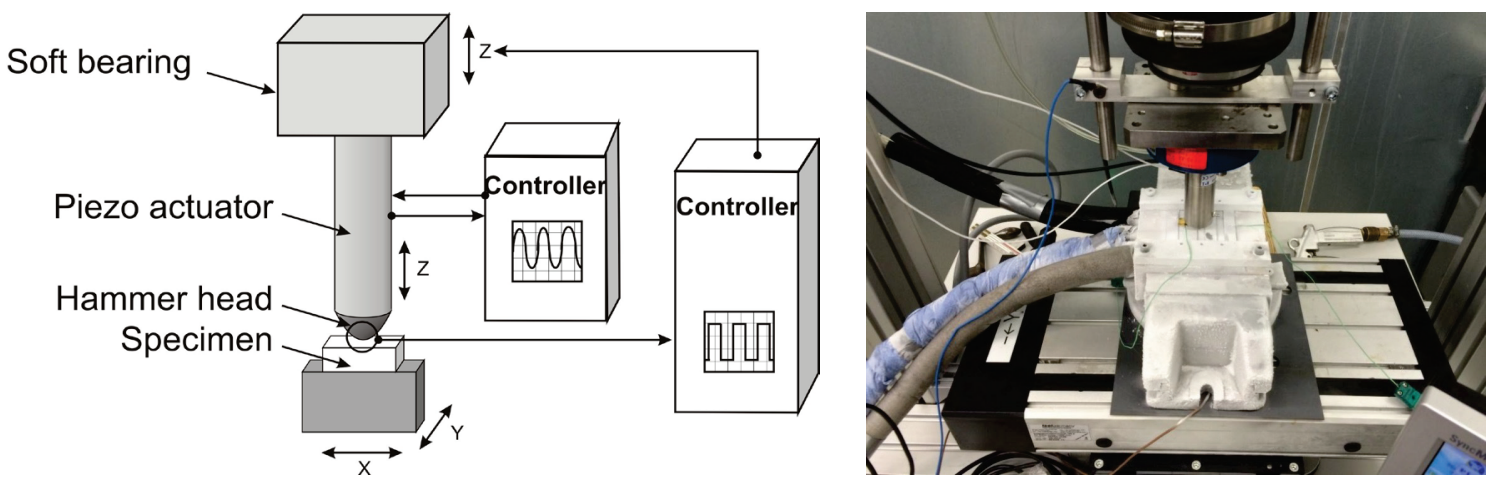

Figure 1: Piezo peening process (schematic, left) [2] and test bench for cryogenic peening at KIT (right)

Low alloy steel AISI 4140 with hardness of $430 \mathrm{HV} 1$ was used for the investigations. The chemical composition is shown in Table 1 . The material was austenitized at $850{ }^{\circ} \mathrm{C}$ for 20 minutes, oil-quenched and then tempered at $450{ }^{\circ} \mathrm{C}$ for 120 minutes. Afterwards, it was furnace-cooled to room temperature.

Table 1: Chemical composition of AISI 4140

\begin{tabular}{|c|c|c|c|c|c|c|}
\hline \multicolumn{7}{|c|}{ Chemical composition (wt.-\%) } \\
\hline Fe & $\mathrm{C}$ & $\mathrm{Cr}$ & $\mathrm{Mo}$ & $\mathrm{Mn}$ & $\mathrm{Si}$ & $\mathrm{Ni}$ \\
\hline Base & 0.425 & 1.011 & 0.222 & 0.803 & 0.252 & 0.101 \\
\hline
\end{tabular}

Flat specimens with a thickness of $4 \mathrm{~mm}$ (Fig. 2) were used throughout the experimental investigations. piezo peening was carried out on an area of $10 * 10 \mathrm{~mm}^{2}$. Near-surface residual stresses were evaluated in the center of the peened area, using $\mathrm{Cr}-\mathrm{K} \alpha$ radiation on $\{211\}-\alpha$-ferrite diffraction line at $2 \theta=156.4^{\circ}$. X-ray stress analysis was carried out according to the $\sin ^{2}(\psi)$ method [5], using $\mathrm{E}\{211\}=220 \mathrm{GPa}$ and $v\{211\}=0.28$ as Young's modulus and Poisson's ratio, respectively. Residual stress depth profiles were determined by incremental electrolytic layer removal. Comparability of experiment and simulation was established by FE layer removal simulation. A detailed description of the experimental setup and residual stress measurements can be found in [2].

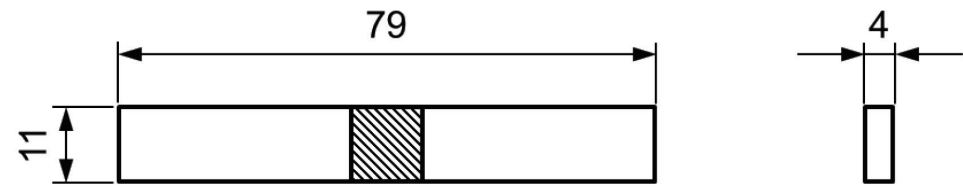

Figure 2: Specimen geometry with peened area (hatched) 


\section{Finite Element Simulation}

The commercially available equation solver Abaqus/Explicit was used for stress computation due to its suitability for nonlinear, dynamic problems. FE geometry and mesh were modeled using parameterization. Material data were implemented as user material subroutine (VUMAT) Fortran77 code. A $2 * 2 * 2 \mathrm{~mm}^{3}$ sized cuboid consisting of approx. 860,000 hexahedron elements of type C3D8R was used as simulation model and is shown in Fig. 3 (left).
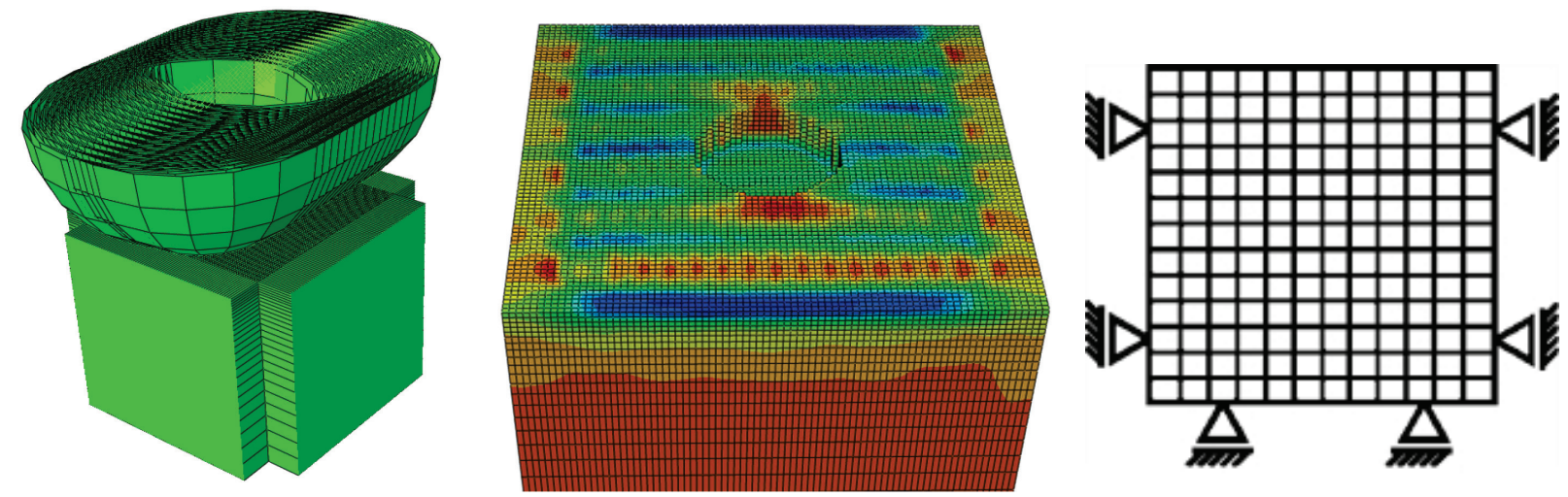

Figure 3: FE geometry model (left), element layer removal (middle) and boundary conditions (right)

For proper resolution, mesh refinement was introduced towards the impact surface. Semi-infinite elements of type CIN3D8 were used at the laterals to dampen the stress waves induced by the impact of the hammer head on the surface. Hammer heads were modeled as rigid half-spheres (Fig. 3, left), which is valid if the yield strength ratio of hammer head and work piece exceeds a value of 2.0 [6]. Eight consecutive impacts were simulated on $1.8 \mathrm{~mm}$ length, using an imposed sinusoidal hammer head movement and an individual hammer head model for each stroke. General contact with a friction coefficient of $\mu=0.4$ was defined between hammer head and work piece. A postcomputation Python script was used to evaluate the residual stress state. Residual stresses were determined in a circular area; cf. Fig. 3 (middle). Stress redistribution due to electrolytic layer removal was realized by successively setting Young's modulus to zero in near-surface layers. After each layer, the mean value of superficial residual stresses within the area was determined. By this means, comparability between experiment and simulation was established. Floating boundary conditions as illustrated in Fig. 3 (right) were chosen to impede horizontal movement of the laterals and vertical movement of the underside. Furthermore, variable mass scaling, as described in [3], was applied.

The physically based, elastic-viscoplastic material model for BCC materials presented in [3] was used to describe the material behavior in the present strain, strain-rate and temperature range. Changes in strain-rate and temperature mainly affect the yield strength, whereas hardening curves remain similar in a wide range of temperature and strain rate [7]. This effect is due to thermally activated deformation [8] and allows for modeling a viscoplastic "overstress" independently of work hardening [7]. Combined nonlinear isotropic and kinematic hardening as proposed by [9] was applied to account for the Bauschinger effect. It was shown in literature that including kinematic hardening leads to a more realistic description of simulations of shot peening and machine hammer peening [3, $9,10]$.

The framework of small strains was adopted, thus assuming additive decomposition of the strain tensor in elastic and plastic parts. The consistent viscoplasticity approach [11] was used together with the von Mises yield criterion, which reads

$$
\mathrm{f} \equiv \mathrm{J}_{2}\left(\boldsymbol{\sigma}^{\prime}-\boldsymbol{\xi}\right)-\mathrm{R}-\sigma_{\mathrm{G}}-\sigma^{*}=0,
$$


where $\xi$ and $\mathrm{R}$ denote the kinematic and the isotropic hardening variables, respectively. Two additive nonlinear kinematic variables and one nonlinear cyclic isotropic variable as proposed by [12] and [13], respectively, were applied. A full description of the constitutive equations can be found in [7] and [3]. The variables $\sigma_{\mathrm{G}}$ and $\sigma^{*}$ denote the athermal and thermal parts of the flow stress, respectively [8]. The former slightly depends on temperature, whereas the latter shows strong dependence on temperature and strain-rate. The constitutive formula developed by [8] was used to reproduce the experimentally obtained flow stresses. As can be seen from Fig. 4, the thermal flow stress parts can be increased by higher strain-rates, and even more pronounced, by lower temperatures. Three temperatures were chosen for the investigations: cryogenic $\left(-180^{\circ} \mathrm{C}\right)$; ambient $\left(20^{\circ} \mathrm{C}\right)$ and warm $\left(200{ }^{\circ} \mathrm{C}\right)$. Young's modulus was determined a priori and set to 225,210 and 194 $\mathrm{GPa}$, respectively. Thus, flow stresses during piezo peening at varying temperatures, where strainrates about $100 / \mathrm{s}$ apply at a peening frequency of $500 \mathrm{~Hz}$, are adequately reproduced. The full constitutive parameter set can be found in [3].

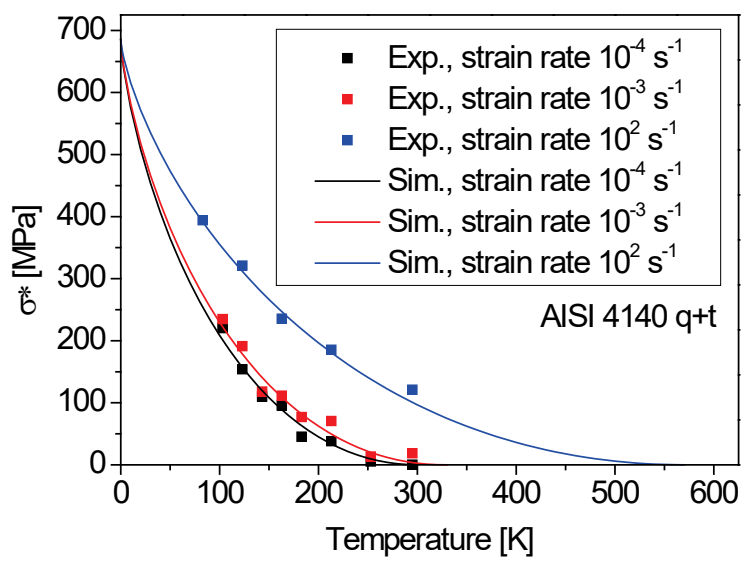

Figure 4: Strain-rate and temperature dependent thermal flow stress part [3]

\section{Results and Discussion}

Experimental standard process parameters are summarized in Table 2. Besides the temperature, either stepover distance or stroke was varied while all other process parameters remained unchanged throughout the investigations.

Table 2: Standard process parameters

\begin{tabular}{|c|c|c|c|c|}
\hline Frequency & $\begin{array}{c}\text { Hammer head } \\
\text { material }\end{array}$ & $\begin{array}{c}\text { Hammer head } \\
\text { diameter }\end{array}$ & Stroke & Feed rate \\
\hline $500 \mathrm{~Hz}$ & WC-Co & $5 \mathrm{~mm}$ & $36 \mu \mathrm{m}$ & $50 \mathrm{~mm} / \mathrm{s}$ \\
\hline
\end{tabular}

Fig. 5 shows transverse (left) and longitudinal (right) residual stress profiles determined experimentally after piezo peening at different temperatures and stepover distances with $36 \mu \mathrm{m}$ stroke. At all temperatures, residual stress penetration depths increase by reducing stepover distance, which is a usually observed effect [2]. Furthermore, three effects seem to apply: A slight increase in penetration depth could possibly be assumed for cryogenic temperatures, regardless of stepover distance and measurement direction. The effect of stepover distance on residual stress penetration depth seems to be more pronounced at cryogenic and less pronounced at elevated temperatures. Furthermore, cryogenic temperatures appear to shift residual stress maxima below the surface, while maximum residual stresses can be found on the surface after warm peening. This effect can probably be explained by an increasing dominance of Hertzian pressure caused by the cooling to cryogenic temperatures, which is typical for hard work pieces [14]. 

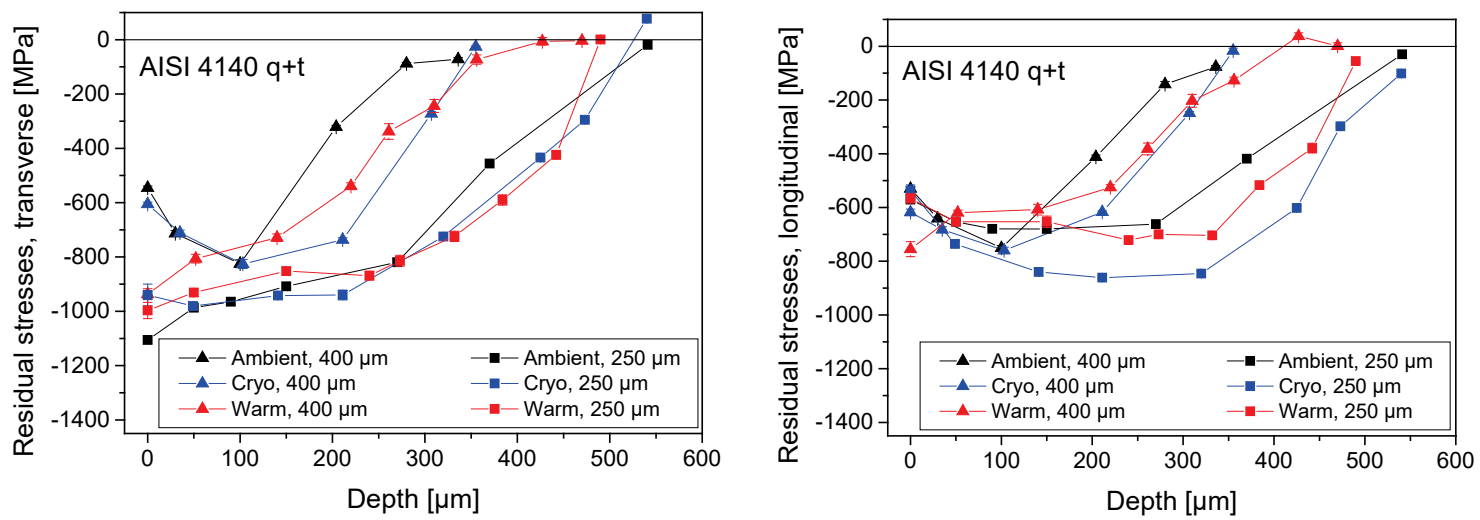

Figure 5: Experimentally determined transverse (left) and longitudinal (right) residual stress depth distributions for different temperatures and stepover distances

The question arises whether such effects can be reproduced by the strain-rate and temperature dependent FE simulation. A comparison of experimentally and numerically determined residual stress profiles with varying stroke $(36$ and $48 \mu \mathrm{m})$ and stepover distance $(400$ and $250 \mu \mathrm{m})$ is shown in Fig. 6 (left). For the sake of clarity, only transverse residual stresses are considered here.
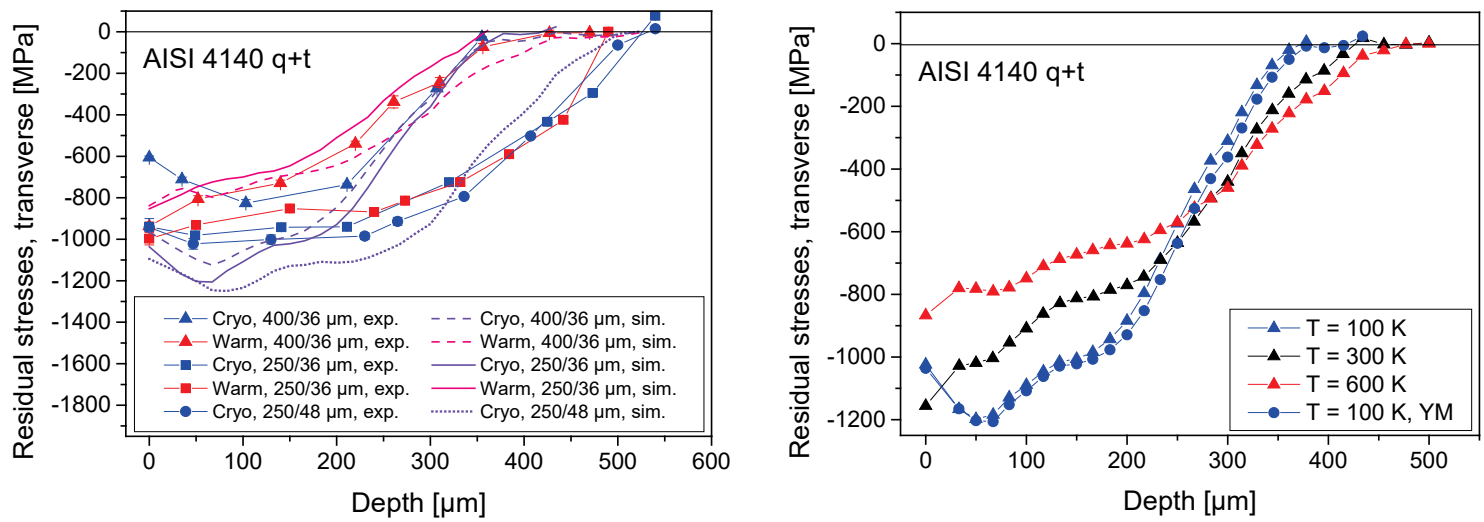

Figure 6: Comparison of residual stress depth distributions (left) and simulation properties (right)

As can be seen from Fig. 6 (left), generally satisfactory agreement was achieved between simulation and experiment. However, a certain discrepancy regarding the penetration depths could be seen for $250 \mu \mathrm{m}$ stepover distance. Cryogenic peening with $48 \mu \mathrm{m}$ stroke hardly affects residual stresses induced by the peening experiment, which is probably caused by the limited rigidity of the test bench. Despite the underestimation of residual stress penetration depths, the experimentally observed shift of residual stress maxima below the surface at cryogenic temperatures can also be recognized in the simulations. Contradictory to the experiment, numerically obtained residual stress penetration depths after warm peening increase for each stepover distance. However, this effect was shown to be an intrinsic property of strain-rate dependent material models [15] and is illustrated in Fig. 6 (right): Higher temperatures and lower strain-rates lead to lower maximum residual stresses and higher residual stress penetration depths and vice versa. Young's modulus, varied from 225 to $210 \mathrm{GPa}$ (denoted by "YM" in Fig. 6, right), has only limited influence upon residual stress generation.

An adequate constitutive description of flow stresses is decisive for any simulation of residual stress generation. Yet, the prevailing deformation mechanisms are expected to be more complex than modeled in this investigation. For instance, the process was modeled adiabatically, which may not be entirely valid, especially for larger work pieces. Those remaining issues in material modeling for simulations of MHP processes are therefore still subject to thorough investigations of ongoing work. 


\section{Summary}

Experimentally and numerically obtained residual stress profiles after piezo peening at temperatures between -180 and $+200{ }^{\circ} \mathrm{C}$ were presented in this paper. Agreement between simulation and experiment for different parameters is found applying a strain-rate and temperature dependent material model in the simulations. Contrary tendencies concerning residual stress penetration depths were found, but may be attributed to the material model definition. More attention should be devoted to a real process description, taking into account the prevailing deformation mechanisms and process conditions.

\section{Acknowledgement}

Results have been derived within the international ERANET-CORNET research project HaPTec "Further qualification of machine hammer peening technology for industrial use".

\section{References}

[1] V. Schulze, F. Bleicher, P. Groche, Y. B. Guo, Y. S. Pyun, Surface Modification by Machine Hammer Peening and Burnishing, submitted to Proc. CIRP (2016). http://dx.doi.org/10.1016/j.cirp.2016.05.005

[2] F. Lienert, J. Hoffmeister, V. Schulze, Residual Stress Depth Distribution after Piezo Peening of Quenched and Tempered AISI 4140, MSF, vol. 768-769 (2013), pp. 526-533. http://dx.doi.org/10.4028/www.scientific.net/MSF.768-769.526

[3] A. Klumpp, F. Lienert, S. Dietrich, V. Schulze, Residual Stresses after Piezo Peening Treatment predicted by FEM Simulation, in Proc. IDE (2015), pp. 105-115.

[4] A. Klumpp, J. Hoffmeister, V. Schulze, Mechanical Surface Treatments, in Proc. ICSP 12 (2014), pp. 12-24.

[5] E. Macherauch, P. Müller, Das sin2 psi-Verfahren der röntgenographischen Spannungsmessung, Zeitschrift für angewandte Physik, vol. 13, no. 7 (1961), p. 305.

[6] K.-I. Mori, K. Osakada, N. Matsuoka, Rigid-plastic finite element simulation of peening process with plastically deforming shot, JSME Int. J. (A), vol. 39, no. 3 (1996), pp. 306-312.

[7] G. Z. Voyiadjis, F. H. Abed, A coupled temperature and strain rate dependent yield function for dynamic deformations of bcc metals, Int. J. Plas., vol. 22, no. 8 (2006), pp. 1398-1431. http://dx.doi.org/10.1016/j.ijplas.2005.10.005

[8] U. F. Kocks, A. S. Argon, M. F. Ashby, in: Progress in materials science, Thermodynamics and Kinetics of Slip, vol. 19 (1975), pp. 110-170.

[9] M. Klemenz, V. Schulze, O. Vöhringer, D. Löhe, Finite Element Simulation of the Residual Stress States after Shot Peening, MSF, vol. 524-525 (2006), pp. 349-354. http://dx.doi.org/10.4028/www.scientific.net/MSF.524-525.349

[10] E. Rouhaud, A. Ouakka, C. Ould, J. L. Chaboche, M. François, Finite elements model of shot peening, effects of constitutive laws of the material, in Proc. ICSP 9 (2005), pp. 107-112.

[11] A. Carosio, K. Willam, G. Etse, On the consistency of viscoplastic formulations, Int. J. of Solids and Structures, vol. 37, no. 48-50 (2000), pp. 7349-7369. http://dx.doi.org/10.1016/S00207683(00)00202-X

[12] J.-L. Chaboche, Time-independent constitutive theories for cyclic plasticity, Int. J. Plasticity, vol. 2, no. 2 (1986), pp. 149-188. http://dx.doi.org/10.1016/0749-6419(86)90010-0

[13] D. Lee, F. Zaverl, A generalized strain rate dependent constitutive equation for anisotropic metals, Acta Metallurgica, vol. 26, no. 11 (1978), pp. 1771-1780. http://dx.doi.org/10.1016/00016160(78)90088-3

[14] V. Schulze, Modern mechanical surface treatment: states, stability, effects, first ed., John Wiley \& Sons, Weinheim, 2006.

[15] S. A. Meguid, G. Shagal, J. C. Stranart, 3D FE analysis of peening of strain-rate sensitive materials using multiple impingement model, Int. J. of Impact Eng., vol. 27, no. 2 (2002), pp. 119-134. http://dx.doi.org/10.1016/S0734-743X(01)00043-4 